\title{
Research on the Surface Fractal Characteristic of the Rock with Rockburst Proneness
}

\author{
https://doi.org/10.3991/ijoe.v12i12.6454 \\ LI Mo-xiao, SONG Ying-hua, ZHANG Guang, CHEN Jing-xi \\ Wuhan University of Technology, Wuhan, China
}

\begin{abstract}
In order to strengthen the prediction of rockburst and inquire the relationship between the rockburst proneness of rock and its surface fractal characteristic, the surface fractal of the rock was studied by fractal method and uniaxial compression test. The change rules of surface fractal of different types of rock were compared by calculating its fractal dimension of rock before experiment and after experiment. Based on the prediction results, we found that the dimension after test is bigger than before test for four kinds of rocks. The rock with stronger rockburst proneness has more intense failure in the loading process and its crack morphology is more complex.
\end{abstract}

Index Terms-fractal, rockburst, rockburst proneness, uniaxial compression

\section{INTRODUCTION}

With the great progress of social and economic, more and more underground engineering gradually developed deeper. Rockburst is increasingly becoming one of the major geological disasters in the development of underground engineering. Rockburst is a nonlinear dynamic phenomenon that rock mass along the international airport of excavation surface release energy [1]. It is a complicated problem and there is neither a set of mature theory in use of prediction in nor systematic and comprehensive understanding its reasons because of complicated problems existing in the rockburst and different theories of grading. Many scholars consider the rockburst as a unique property of rock itself [2]. Fractal geometry was introduced to analysis the rock damage and fracture by Xie Heping, and it indicates a new development direction for rockburst[3].

Recent researches showed that the fractal phenomenon is remarkable during the breaking process of rock fracture. The distribution and geometry of the fracture have fractal structure [4]. The change of fractal dimension of rock during its deformation process was in concert with its stress state, mechanical properties, physical and chemical properties after many researches [5]. In this paper, we selected marble, granite, hornfels and skarn to carry out uniaxial compression experiment. We study the change rule of rock's surface fractal dimension by collecting and analyzing the surface characteristic of rock before and after test. Based on this, we study the relationship between surface fractal dimension and the rockburst proneness.

\section{EXPERIMENTAL}

In order to study the characteristics of surface fractal of different rocks, the experiment selects marble, granite, hornfels and skarn to conduct uniaxial compression test.
Our samples are conventional standard cylinder with a size of $\Phi 50 \mathrm{~mm} \times 100 \mathrm{~mm}$.

In this experiment we use burst energy index and elastic deformation energy index to measure the strength of rockburst proneness [6]-[7].

Uiaxial compression test used MTS815.04-type rock mechanics test system developed by Wuhan Institute of Rock and Soil Mechanics, Chinese Academy of Sciences.

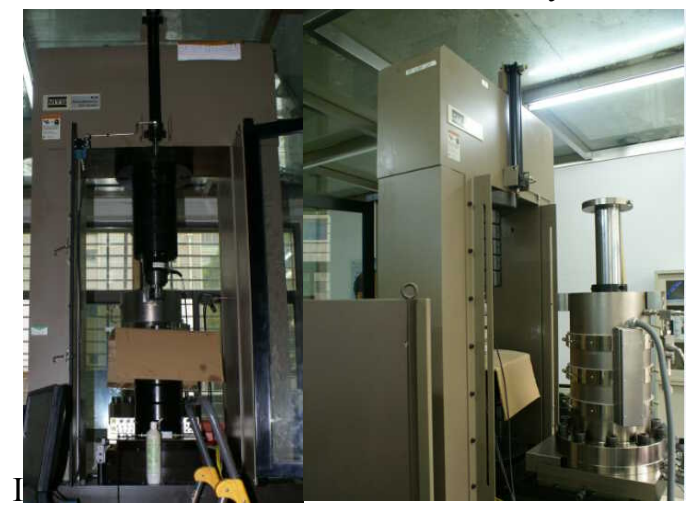

Figure 1. MTS815.04-type rock mechanics test system

The value of each rockburst proneness index of each rock was calculated by using MATLAB. The result is given in table.1.

From the table we can see that granite had a strong tendency to rockburst and the rockburst proneness of hornfels and skarn were relatively weak, the marble' $s$ rockburst proneness was weakest. The strength of rockburst proneness of three rocks arrange in order of: granite $>$ hornfels $>$ skarn $>$ marble.

\section{RESUlt AND DisSCUSION}

\section{A. The extraction of the surface characteristics of rock.}

We have to take pictures of four rocks before and after test. In order to obtain surface features of rock before and after the test as far as possible we must use the professional digital camera. Try to make sure the picture have the high image definition and uniform brightness in case of a large area of the shadow. To be sure the camera lens is perpendicular to the surface in case image deformation. In order to ensure the consistency of the image before and after the test we should placed the specimens in the same position [8]. We selected the same position of the specimen as far as possible to analysis the surface fractal feature and the picture after test contains at least one crack. Then we used MATLAB software to further manipulation the chosen picture. The whole 


\section{SHORT PAPER}

\section{RESEARCH ON THE Surface Fractal CHARACTERISTIC OF THE ROCK WITH RockBurst Proneness}

process is: choose the surface image of rock $\rightarrow$ convert the image to binary image $\rightarrow$ edge detection $\rightarrow$ the calculation of fractal dimension. The analysis processes of a sample chosen from marble are as follows.

TABLE I. THE RESULT OF BURST ENERGY INDEX AND ELASTIC DEFORMATION ENERGY INDEX OF EACH ROCK

\begin{tabular}{|c|c|c|c|}
\hline Sample & $\begin{array}{c}\text { Uniaxial } \\
\text { compressive } \\
\text { strength } \\
\text { (Mpa) }\end{array}$ & $\begin{array}{c}\text { Burst } \\
\text { energy } \\
\text { index }\end{array}$ & $\begin{array}{c}\text { Elastic } \\
\text { deformation } \\
\text { energy index }\end{array}$ \\
\hline DH4 & 54.74 & 1.50 & - \\
\hline DH5 & 53.15 & 1.32 & - \\
\hline DH8 & 54.84 & 1.06 & - \\
\hline DH6 & 92.32 & - & 1.91 \\
\hline DH9 & 83.62 & - & 1.72 \\
\hline HB1 & 117.18 & 2.31 & - \\
\hline HB2 & 311.24 & 3.00 & - \\
\hline HB4 & 189.20 & 1.71 & - \\
\hline HB6 & 151.34 & - & 6.15 \\
\hline HB7 & 245.60 & - & 6.17 \\
\hline JY3 & 109.86 & 1.10 & - \\
\hline JY4 & 84.18 & 2.00 & - \\
\hline JY8 & 125.61 & - & 5.21 \\
\hline X3 & 97.38 & - & 2.16 \\
\hline X4 & 113.99 & 1.22 & - \\
\hline X6 & 98.26 & - & 2.17 \\
\hline X8 & 146.95 & 1.42 & - \\
\hline X10 & 85.98 & 1.37 & - \\
\hline The 44196964
\end{tabular}

The surface image of rock was selected by using a $64 \mathrm{x}$ 64 pixel block. The specific operations are as follows.

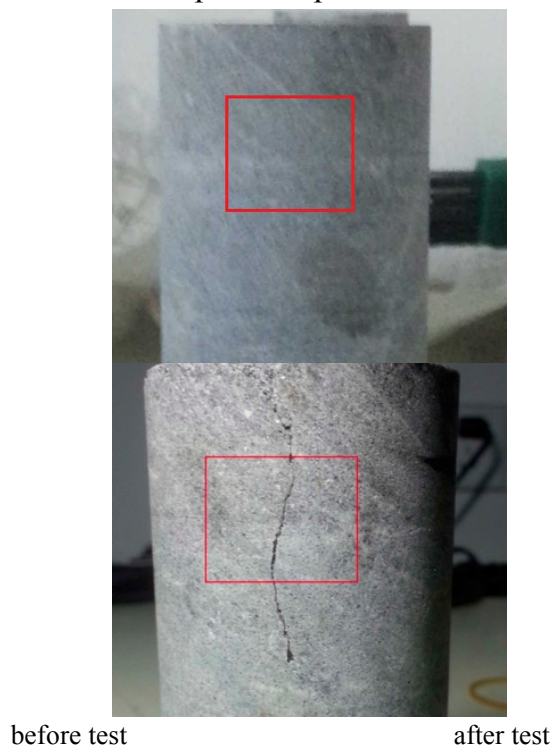

Figure 2. The selected position of surface feature before and after test of marble

In the Fig.2, the red block is the part of surface feature we selected. The image after extraction is show in Fig.3.

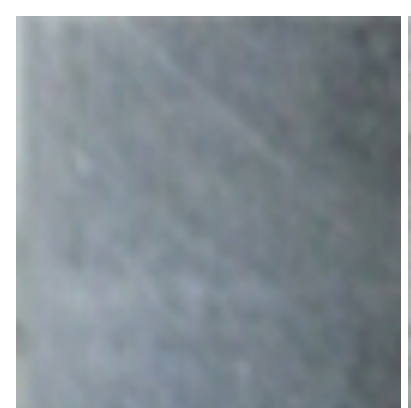

before test

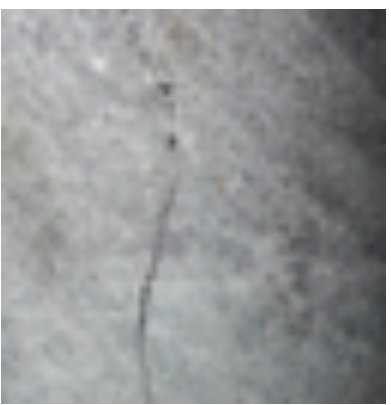

after test
Figure 3. The image of surface feature before and after test of marble

The image in the Fig. 3 was processed by our own image processing program which programmed by MATLAB8.0. The image noise reduction is the first step of processing. The surface feature of rock is more distinct after this step so it is facilitate to the next step of the work. The processed image is show in Fig. 4.

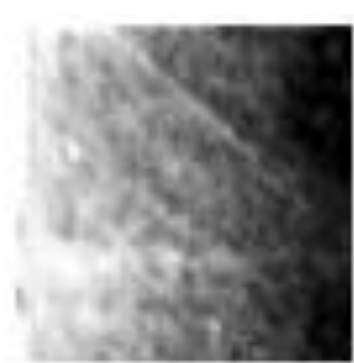

before test

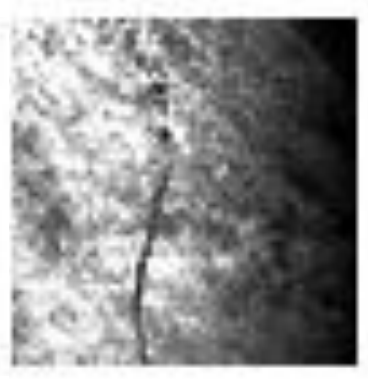

after test
Figure 4. The processed image of surface feature before and after test of marble (step1)

The next step is converting the denoised image into binary image so the fractal dimension can be calculated by MATLAB8.0. The binary image is show in Fig.5.

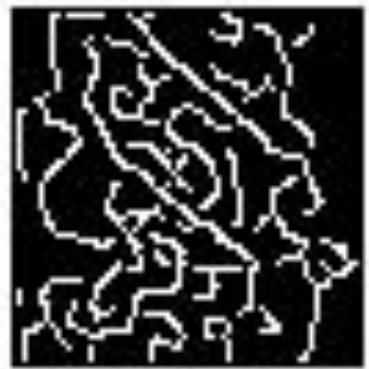

before test

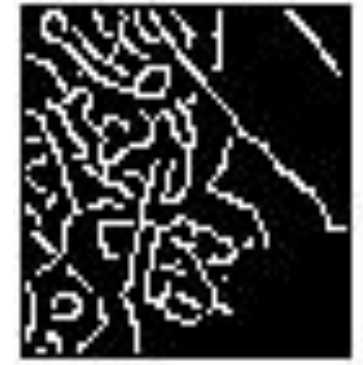

after test
Figure 5. The binary image of surface feature before and after test of marble (step2)

\section{B. The calculation of fractal dimension of rock before and after test.}

The image in Fig. 5 is divided by $2 \times 2$ pixels block, $3 \times 3$ pixels block, $\cdots, 64 \times 64$ pixels block. $\mathrm{W}$ is the number of non empty square partition in the graph and $r$ is measurement scale (the scale of block). The dimension can be determined by the linear regression of the $\mathrm{W}$ and $\mathrm{r}$ in the double logarithmic coordinate. The value of dimension is the absolute value of the slope of the line fitting. The result of calculating is show in Fig.6. 


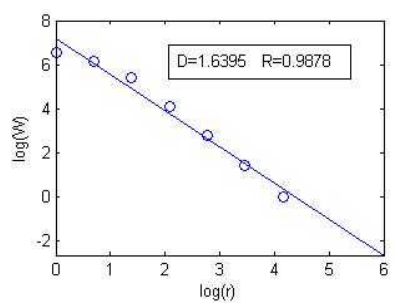

before test

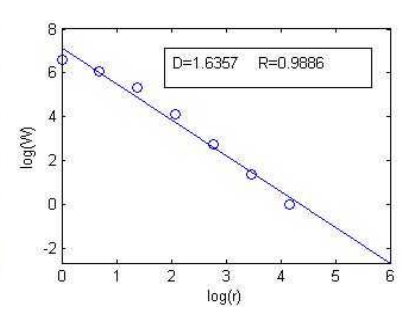

after test
Figure 6. The result of calculating of fractal dimension of marble

The Fig.6 shows that the correlation coefficient of surface fractal dimension fitting chart of granite are more than 0.98 . The fitting result means that the surface of rock shows the fractal characteristics. Repeat the above steps to calculate the dimension of others rocks and the result is show in Table II.

TABLE II. RESULT OF SURFACE FRACTAL DIMENSION OF EACH ROCK

\begin{tabular}{|c|c|c|c|c|c|c|}
\hline \multirow{2}{*}{ Type } & \multirow{2}{*}{$\begin{array}{l}\text { Nm- } \\
\text { ber }\end{array}$} & \multicolumn{2}{|c|}{$\begin{array}{l}\text { Dimension } \\
\text { before test }\end{array}$} & \multicolumn{2}{|c|}{$\begin{array}{c}\text { Dimension } \\
\text { after test }\end{array}$} & \multirow{2}{*}{$\begin{array}{c}\text { Change } \\
\text { of } \\
\text { dimen- } \\
\text { sion }\end{array}$} \\
\hline & & $\begin{array}{l}\text { Dim- } \\
\text { ension }\end{array}$ & $\begin{array}{l}\text { Aver } \\
\text {-age }\end{array}$ & $\begin{array}{l}\text { Dim- } \\
\text { ension }\end{array}$ & $\begin{array}{l}\text { Aver } \\
\text {-age }\end{array}$ & \\
\hline \multirow{7}{*}{$\begin{array}{l}\text { Ma- } \\
\text { rble }\end{array}$} & $\begin{array}{c}\mathrm{DH} \\
5\end{array}$ & $\begin{array}{c}1.639 \\
1\end{array}$ & \multirow{7}{*}{$\begin{array}{c}1.63 \\
80\end{array}$} & $\begin{array}{c}1.635 \\
7\end{array}$ & \multirow{7}{*}{$\begin{array}{c}1.64 \\
50\end{array}$} & \multirow{7}{*}{0.0070} \\
\hline & $\mathrm{DH}$ & 1.653 & & 1.698 & & \\
\hline & 6 & 8 & & 6 & & \\
\hline & $\mathrm{DH}$ & 1.599 & & 1.589 & & \\
\hline & 8 & 8 & & 6 & & \\
\hline & $\mathrm{DH}$ & 1.659 & & 1.656 & & \\
\hline & 9 & 0 & & 0 & & \\
\hline \multirow{4}{*}{$\begin{array}{l}\text { Gra- } \\
\text { nite }\end{array}$} & HB & 1.619 & \multirow{4}{*}{$\begin{array}{c}1.62 \\
31\end{array}$} & 1.661 & \multirow{4}{*}{$\begin{array}{c}1.65 \\
52\end{array}$} & \multirow{4}{*}{0.0321} \\
\hline & 6 & 0 & & 1 & & \\
\hline & HB & 1.627 & & 1.649 & & \\
\hline & 7 & 1 & & 2 & & \\
\hline \multirow{4}{*}{$\begin{array}{c}\text { Horn } \\
- \\
\text { fels }\end{array}$} & IY & 1.675 & \multirow{4}{*}{$\begin{array}{c}1.65 \\
87\end{array}$} & 1.654 & \multirow{4}{*}{$\begin{array}{c}1.66 \\
64\end{array}$} & \multirow{4}{*}{0.0077} \\
\hline & JY4 & 9 & & 0 & & \\
\hline & JY8 & 1.641 & & 1.678 & & \\
\hline & JY8 & 4 & & 7 & & \\
\hline \multirow{4}{*}{$\begin{array}{c}\text { Skar } \\
\mathrm{n}\end{array}$} & X3 & 1.575 & \multirow{4}{*}{$\begin{array}{c}1.62 \\
72\end{array}$} & 1.609 & \multirow{4}{*}{$\begin{array}{c}1.64 \\
70\end{array}$} & \multirow{4}{*}{0.0198} \\
\hline & & 1.630 & & 1.605 & & \\
\hline & X6 & 5 & & 8 & & \\
\hline & $\mathrm{X} 10$ & $\begin{array}{c}1.675 \\
6\end{array}$ & & $\begin{array}{c}1.694 \\
5\end{array}$ & & \\
\hline
\end{tabular}

In the Table II it shows that the surface fractal dimensions of four rocks have increased. The amplification of granite is about $2 \%$ and the amplification of skarn is about $1 \%$. The amplification of marble and hornfels are both below $1 \%$. The strength of rockburst proneness of three rocks arrange in order of: granite> hornfels $>$ skarn $>$ marble. According to the result the rock of stronger rockburst proneness have bigger change of dimension between before an after test. The dimension after test is bigger than before test for four kinds of rocks. That is because the surfaces of rock cracked after test and have more complex features. The more complex surface has a bigger dimension. The rock with stronger rockburst proneness has more intense failure in the loading process and its crack morphology is more complex. So its change of dimension during the test is bigger. Given all that, the change of dimension during the uniaxial compression can be used to judge the strength of rockburst proneness of rock.

\section{CONCLUSION}

Calculated four kinds of rock's surface fractal dimension during the uniaxial compression and found that the dimension after test is bigger than before test for four kinds of rocks. The rock with stronger rockburst proneness has more intense failure in the loading process and its crack morphology is more complex. The change of dimension during the uniaxial compression can be used to judge the strength of rockburst proneness of rock. In this paper, when the change of dimension over 0.03 the rock have stronger rockburst proneness.

\section{REFERENCES}

[1] He Manchao, Miao Jinli, Li Dejian, Wang Chunguang. Experimental study on rockburst processes of granite specimen at great depth [J].Chinese Journal of Rock Mechanics and Engineering, 2007, 26(5): 865 876. ( in chinese )

[2] Cook N G W. The basic mechanics of rockbursts [J]. SAIMM, 1966, 66(1): 56-70.

[3] Xie HP. Fractal nature on damage evolution of rock materials [J]. In: Proc. 2nd Int. Symp. On Min. Sci. \& Tech. (CUMT), 1991: 697 704.

[4] Yi Shunmin, Tang Huiming. Fractal Structure features of active fault [J]. Earth Scinece, 1995, 20(1): 58 62. ( in chinese )

[5] $\mathrm{Yu}$ Guangming et al. Advance and prospect in research of evolution of fractal characteristics of rock mass caused by underground mining $[\mathrm{J}]$. Chinese Journal of Rock Mechanics and Engineering, 2004, 23(2 Suppl):4674 4678. (in chinese )

[6] Singh S P. Bursting energy release index [J] . RockMechanics and Rock Engineering, 1988, 21(1): 149 155. https://doi.org/10.1007/BF01043119

[7] Wu Y., Zhang W.. Evaluation of the bursting proneness of coal by means of its failure duration [J]. Rock-bursts and seismicity in mines, Gibowicz and Lasocki eds. Rotterdam: Balkema, 1997:285 288.

[8] Nie Duxian,Zeng Wenqu,Wen Youwei. Fractal Dimension Study of Calculating Method [J]. Microcomputer Development, 2004, 14(9):17 22. (in chinese )

\section{AUTHORS}

Moxiao $\mathbf{L i}$ is with the Wuhan University of Technology, Wuhan, China (mayshine-1988@163.com).

Yinghua Song is with the Wuhan University of Technology, Wuhan, China (song6688c@163.com).

Guang Zhang is with the Wuhan University of Technology, Wuhan, China (Gzhang58@163.com).

Jinxi Chen is with the Wuhan University of Technology, Wuhan, China (jxchen60@163.com).

This work was supported in part by the Specialized Research Fund for the doctoral college (NO.20120143110005). Submitted 26 October 2016. Published as resubmitted by the authors 27 November 2016. 